\title{
PRESERVASI DIGITAL SEBAGAI TINDAKAN PREVENTIF UNTUK MELINDUNGI BAHAN PUSTAKA SEBAGAI BENDA BUDAYA
}

\author{
Arienda Addis Prasetyo \\ Program Studi Ilmu Perpustakaan dan Sains Informasi \\ Universitas Wijaya Kusuma Surabaya \\ Email: ariendaddisprasetyo@gmail.com
}

\begin{abstract}
ABSTRAK
Perpustakaan sebagai bagian dari Lembaga Pusat Dokumentasi dan Informasi perlu mengikuti perkembangan teknologi informasi, peraturan pemerintah serta dinamika yang terjadi di masyarakat. Tak lepas juga Lokananta dan Produksi Film Negara (PFN) sebagai lembaga dokumentasi elektronik dituntut untuk menyelamatkan nilai informasi agar dapat dimanfaatkan dalam waktu yang relatif lebih lama. Oleh sebab itu perlu dilakukannya beberapa tahap langkah preventif yakni Preservasi teknologi (technology preservation), Preservasi dengan cara penyegaran atau pembaruan (refreshing), Preservasi dengan cara melakukan migrasi dan format ulang (migration and reformating), Preservasi dengan cara emulasi (emulation), Arkeologi dan Preservasi dengan cara mengubah data digital menjadi analog.
\end{abstract}

Kata Kunci: Benda Budaya, Bahan Pustaka, Preservasi.

\section{PENDAHULUAN}

Perpustakaan adalah institusi

yang mengumpulkan pengetahuan tercetak dan terekam, mengelolanya dengan cara khusus guna memenuhi kebutuhan intelektualitas para penggunanya melalui beragam cara interaksi pengetahuan. Berbagai jenis perpustakaan di Indonesia dapat di kelompokan berdasarkan lembaga yang menanganinya, diantaranya

Perpustakaan Nasional, Perpustakaan Umum, Perpustakaan

Sekolah/Madrasah, Perpustakaan
Perguruan Tinggi dan Perpustakaan Khusus. (Undang-Undang No.43 Tahun 2007 tentang Perpustakaan pada Bab VII Pasal 20)

$$
\text { Faktor utama dalam }
$$
menentukan kualitas perpustakaan salah satunya dilihat dari koleksi perpustakaan. Menurut Ade Kohar (2003:6), koleksi perpustakaan adalah mencangkup berbagai format bahan sesuai dengan perkembangan dan kebutuhan alternatif para pemakai perpustakaan terhadap media rekam informasi. Sedangkan secara khusus, 
koleksi perpustakaan adalah inti sebuah perpustakaan dan menentukan kebutuhan layanan. Dapat disimpulkan bahwa, salah satu kriteria dalam penilaian layanan perpustakaan melalui kualitas

koleksinya. Sehingga koleksi perpustakaan merupakan aset dalam perpustakaan tersebut, hal demikian koleksi perpustakaan sangat penting untuk dilakukan preservasi untuk menjaga koleksinya.

Padahal selain kegiatan rutin yang bersifat layanan seperti layanan peminjaman, layanan penelusuran informasi, dan manajemen informasi. Kegiatan preservasi sangatlah penting dilakukan untuk menjaga bahan pustaka tersebut untuk melindungi dari faktor bencana baik yang ditimbulkan oleh manusia maupun alam yang mengancam keberadaan dan kelangsungan sumber-sumber informasi tersebut. Menurut Lasa, H.S (2007:233234) Preservasi berarti sistem pengolahan dan perlindungan pada bahan pustaka, dan atau tugas maupun pekerjaan untuk memperbaiki, memugar, melindungi, merawat bahan pustaka, dokumentasi, arsip, maupun bahan informasi serta bangunan perpustakaan. Berbagai kerusakan di perpustakaan tersebut dapat mengancam kelestarian koleksi budaya. Bahan pustaka tersebut memiliki risiko kerusakan, baik dari faktor bahan pustaka itu sendiri maupun faktor dari luar (lingkungan) dan kerusakan karena ulah manusia.

Oleh karena itu perpustakaan sebagai lembaga yang menyimpan bahan pustaka sebagai salah satu benda budaya seperti yang telah dituangkan dalam Konvensi Den Haag (1954) bahwa, "Gedung-gedung yang fungsi dan tujuan utamanya adalah untuk melestarikan atau memamerkan bendabenda budaya yang bergerak sebagaimana dicantumkan dalam ayat seperti museum, perpustakaan (pusat/nasional), gedung penyimpanan arsip-arsip,

tempat-tempat perlindungan atau penyimpanan, yang pada waktu sengketa bersenjata, digunakan untuk menyimpan bendabenda budaya yang bergerak (movable property)" dari pendapat diatas bahwa perpustakaan menyimpan bahan pustaka yang vital sehingga perlunya pelestarian benda budaya tersebut dengan cara melindungi, merawat, memperbaiki bahan pustaka tersebut sehingga 
pengetahuan yang ada dalam benda budaya tersebut tidak hilang.

$$
\text { Dalam ruang lingkup }
$$
perpustakaan preservasi adalah satu pekerjaan yang harus pustakawan kerjakan, salah satunya usaha dalam preservasi untuk mengalihkan isi informasi dari satu bentuk format atau matrik ke bentuk lain. Alih media salah satu usaha dalam pelestarian benda budaya, dengan alasan mereproduksi benda budaya dari bahan asli, termasuk membuat bentuk mikro, fotorepro, dan transformasi ke dalam bentuk digital. Usaha preservasi melalui proses digitalisasi telah diatur pada Peraturan Pemerintah Nomor 88 Tahun 1999 tentang Tata Cara Pengalihan Dokumen Perusahaan ke dalam mikrofilm atau media lainnya yang bukan kertas dengan keamanan tinggi seperti misalnya CD ROM dan WORM.

Koleksi perpustakaan sebagai salah satu benda budaya harus banyak perhatian khusus untuk perawatannya supaya dapat lestari ilmu pengetahuan didalamnya. Seperti kegiatan preservasi naskah di Masjid Agung Surakarta, walaupun sudah dilakukan akan tetapi dapat dikatakan sudah agak terlambat karena naskah yang rusak disebabkan oleh berbagai penyebab. Petugas Perpustakaan Masjid Agung Surakarta, M Zufa Syahrani mengungkapkan, perpustakaan Masjid Agung total memiliki koleksi naskah kuno sebanyak 455 buku. Dari jumlah itu, baru 105 naskah kuno yang telah direstorasi. Sedangkan 350 nasakah kuno lainya belum direstorasi apalagi didigitalisasi. (solopos.com)

Karena keterbatasan sarana prasarananya, dana juga sumber daya manusianya. Perpustakaan Masjid Agung sudah melakukan tahap preservasi secara mandiri, tetapi pelaksanaanya sangat tergantung pada pihak luar. M.Zufa mengatakan bahwa Perpustakaan Masjid Agun pernah dibantu Perpusnas yang menerjunkan tim untuk merestorasi nasakah kuno koleksi Masjid Agung pada 2015. Tapi sangat disayangkan program itu tak berlanjut lagi hingga sekarang. Mereka mengharapkan adanya program restorasi untuk memperbaiki fisik naskah kuno dan program digitalisasi untuk memudahkan pengunjung mengakses naskah kuno.

Adapun rumusan permasalahan dari latar belakang yang disampaikan pada paragraf sebelumnya adalah 
tentang bagaimana melestarikan koleksi budaya seperti naskah, arsip, dan media baik cetak dan noncetak baik bentuk fisik cetak dan non cetak dengan mempertahankan bentuk asli maupun konten (informasi).

\subsection{METODE PENELITIAN}

Jenis penulisan artikel ini adalah kualitatif. Subyek dalam artikel ini adalah informan yang terkait dengan pokok pembahasan. Penentuan informan dilakukan secara purposive sampling.

\subsection{KAJIAN TEORI}

\section{Bahan Pustaka.}

Perpustakaan merupakan sistem informasi yang berfungsi untuk menyediakan dan menyampaikan informasi yang terdapat dalam koleksinya, koleksi pustaka merupakan bagian dari bahan pustaka. Koleksi perpustakaan sangatlah beragam baik cetak ataupu non-cetak seperti buku, naskah kuno dan majalah maupun koleksi non cetak seperti mikrofis, piringan hitam, pita rekaman, $\mathrm{CD}$, kaset, dan sebagainya.

Darmono mengungkapkan pada buku Manajemen Tata Kerja Perpustakaan Sekolah (2001:60),
Koleksi adalah sekumpulan rekaman informasi dalam berbagai bentuk tercetak (buku, majalah, surat kabar) dan bentuk tidak tercetak (bentuk mikro, bahan audio visual, peta). Ditambahkan lagi menurut Ade Kohar (2003:6), bahan pustaka adalah koleksi yang mencangkup berbagai format bahan sesuai dengan perkembangan dan kebutuhan alternative para pemakai perpustakaan terhadap media rekam informasi. Dari pendapat yang telah diungkapkan diatas dapat disimpulkan bahwa bahan pustaka merupakan semua koleksi yang dikumpulkan, diolah, dan disimpan di perpustakaan untuk karena muatan informasi berbagai bidang ilmu pengetahuan, teknologi dan kebudayaan. Disajikan kepada masyarakat guna memenuhi kebutuhan pengguna akan informasi dan pengatahuan di dalamnya.

\section{Benda Budaya}

Menurut Konvensi Den Haag (1954) dalam Figra Ardham (2015), maka dapat dilihat bahwa lebih komprehensif (lengkap) jika dibandingkan dengan Roerich Pact. Pasal 1 Konvensi Den Haag 1954 mencantumkan definisi mengenai apa yang dimaksud dengan benda budaya yaitu : 
a. Setiap benda bergerak atau tidak bergerak yang merupakan warisan budaya yang bernilai amat penting bagi manusia, seperti monument-monumen arsitektur, kesenian maupun sejarah baik ynag bersifat keagamaan maupun tidak; situssitus arkeologi, kompleks bangunan yang secara keseluruhan, bernilai historis atau bernilai seni, hasil cipta seni manuskrip, buku dan objek - objek lain yang bernilai seni, sejarah dan arkeologis, demikian koleksi buku pengetahuan dan koleksi penting lainnya atau arsip-arsip maupun reproduksi benda-benda yang telah disebutkan di atas;

b. Gedung-gedung yang fungsi dan tujuan utamanya adalah untuk melestarikan atau memamerkan benda-benda budaya yang bergerak sebagaimana dicantumkan dalam ayat seperti museum, perpustakaan (pusat/nasional), gedung penyimpanan arsip-arsip, tempat-tempat perlindungan atau penyimpanan, yang pada waktu sengketa bersenjata, digunakan untuk menyimpan benda-benda budaya yang bergerak (movable property);

c. Kompleks yang terdiri dari sejumlah besar benda budaya sebagaimana dirumuskan dalam ayat 1 dan 2, yang disebut "kompleks monument".

Sehingga dari Konvensi Den Haag 1954 disimpulkan bahwa benda budaya adalah fisik item yang merupakan bagian dari warisan budaya dari suatu kelompok atau masyarakat. Mereka termasuk barang-barang tersebut sebagai bangunan bersejarah, karya seni, situs arkeologi, perpustakaan dan museum.

\section{Digitalisasi}

Pengertian alih media sebagaimana diatur pada Peraturan Pemerintah Nomor 88 Tahun 1999 tentang Tata Cara Pengalihan Dokumen Perusahaan ke dalam mikrofilm atau media lainnya yang bukan kertas dengan keamanan tinggi seperti misalnya CD ROM dan WORM. Menurut Joan M. Reitz, dalam Rini Kurniawati (2011:11) alih media adalah proses konversi data ke format digital untuk diproses oleh komputer. Di sistem informasi, digitalisasi biasanya mengacu pada konversi teks atau 
gambar yang dicetak (foto, ilustrasi, peta, dll.) ke dalam sinyal biner menggunakan semacam pemindaian perangkat yang memungkinkan hasil yang ditampilkan dilyar computer. Di telekomunikasi, digitalisasi mengacu pada konversi sinyal analog kontinu ke dalam sinyal digital berdenyut. Asosiasi Perpustakaan Penelitian (ARL) telah mengesahkan digitalisasi sebagai opsi pemformatan preservasi yang diterima untuk berbagai materi. dari pengertian tersebut dapat disimpulkan bahwa pengalihmediaan merupakan kegiatan pemindahan informasi dari bentuk tekstual ke elektronik, tanpa mengurangi isi informasinya, dengan catatan media baru yang digunakan menjamin bahwa hasilnya lebih efisien dan efektif. Alih media atau alih bentuk merupakan salah satu model usaha pelestarian yang dilakukan dengan merubah bentuk atau media informasi dari bentuk kertas (tercetak) ke dalam bentuk lain seperti bentuk mikro atau video disk atau bentuk pita magnetik lainnya.

Perkembangan teknologi digital serta internet saat ini telah memberi kemudahan untuk melakukn akses serta mendistribusikan berbagai informasi dalam format digital. Beberapa faktor yang membuat data digital (seperti audio, citra, video dan text) menurut Irma Elvina (2011) dalam Mustofa banyak digunakan antara lain :

a. Mudah diduplikasi dan hasilnya sama dengan aslinya;

b. Murah untuk penduplikasian dan penyimpanan;

c. Mudah disimpan dan kemudian untuk diolah atau diproses lebih lanjut;

d. Serta mudah didistribusikan, baik dengan media disk maupun melalui jaringan seperti internet.

\section{PEMBAHASAN}

Preservasi adalah memperpanjang eksistensi benda budaya. Pengertian istilah konservasi lebih spesifik, yaitu menyangkut penanganan secara fisik setiap benda budaya. Dureau dan Clements (1986) dalam Hartono

(2016:165) menyebutkan, preservasi mencangkup unsur pengelolaan keuangan, cara penyimpanan, tenaga, teknik, dan metode untuk melestarikan bentuk fisik dan kandungan informasi bahan pustaka. Konservasi dapat juga dikatakan teknik yang dipakai untuk melindungi bahan pustaka dari kerusakan dan kehancuran. Lain halnya 
pendapat Feilden dalam Hartono (2016:165), yang menyatakan bahwa pengertian konservasi lebih luas dibandingkan dengan pengertian preservasi. Menurut sumber ini, ada beberapa tingkatan dalam kegiatan konservasi, yaitu Prevention of Deterioration, Preservation, Consolidation, Restoration and Reproduction. Prevention of deterioration merupakan tindakan preventif untuk melindungi benda budaya dengan mengendalikan kondisi lingkungan dan kerusakan lainnya, termasuk cara penanganan, sedangkan preservasi adalah penanganan yang berhubungan langsung dengan benda budaya.

Menurut Len (2001) menjelaskan bahwa hampir dua sepertiga perpustakaan yang mereka survei telah melakukan penelitian mengenai digitalisasi, kecenderungan ini terjadi tahun 1995-1996. Alasan utama banyak perpustakaan umum, museum, penerbit dan sejenisnya melakukan alih media bahan perpustakaan ialah untuk meningkatkan penggunaan koleksi (increases access or sales), juga mengusahakan agar bahan pustaka asli tidak cepat mengalami kerusakan dan untuk menjaga nilai yang terkandung dalam bahan pustaka seperti historisnya.

Upaya perpustakaan untuk mengikuti dinamika yang terjadi di masyarakat tentu bukan pekerjaan mudah. Upaya ini, sekaligus menjadi tantangan yang dihadapi perpustakaan dalam melakukan kegiatan digitalisasi koleksi ke depan. Menurut Beatrice Ayodeji Fabunmi, Mattew Paris, Martins Fabunmi (2006) beberapa tantangan yang dihadapi oleh Perpustakaan dalam kegiatan digitalisasi diantaranya :

a. Ketersediaan Anggaran.

Ketersedianan anggaran menjadi salah satu tantangan yang dihadapi dalam kegiatan digitalisasi. Perpustakaan perlu mengalokasikan anggaran untuk pengadaan perangkat keras, perangkat lunak, pelatihan pustakawan dalam rangka kegiatan digitalisasi dan pengolahan koleksi digital serta membayar tenaga yang terlbat dalam kegiatan digitalisasi.

Sumber anggaran kegiatan digitalisasi ini dapat bersumber dari lembaga induk maupun pihak luar yang 
memiliki perhatian terhadap

kegiatan digitalisasi. Apabila

akan memanfaatkan dana dari

lembaga induk maka pengelola

perpustakaan dapat mengajukan

proposal kepada pemimpin

lembaga induk agar kegiatan

digitalisasi dapat dilakukan pada

tahun anggaran berikutnya.

Perpustakaan juga dapat

menyusun proposal untuk

memperoleh anggran digitalisasi

dari pihak eksternal atau

lembaga donor.

b. Penyusunan Kebijakan, Skala

Prioritas dan Perencanaan.

Tantangan berikutnya yang

dihadapi dalam kegiatan

digitalisasi ke depan adalah

penyusunan kebijakan, skala

prioritas dan perencanaan.

Pimpinan perpustakaan

terkadang kesulitan menyusun

kebijakan kegiatan digitalisasi, untuk itu pimpinan perpustakaan perlu melakukan studi badning ke perpustakaan lain yang ketah melakukan kegiatan digitalisasi koleksi. Dengan studi banding ke perpustakaan lain memungkinkan pimpinan perpustakaan juga mengetahui

bagaimana

perencanaan

digitalisasi di lembaga lain.

Pimpinan perpustakaan perlu memiliki kesadaran bahwa kegiatan digitalisasi merupakan bagian penting dari kegiatan preservasi informasi sehingga kegiatan digitalisasi koleksi menjaid skala prioritas program perpustakaan.

c. Resistensi Staf Perpustaskaan. Tantangan lain yang dihadapi dalam kegiatan digitalisasi ke depan adalah resistensi staf perpustakaan. Minimnya pengetahuan di bidang computer dan digitalisasi menyebabkan tidak semua staf perpustakaan dapat terlibat dalam kegiatan digitalisasi koleksi perpustakaan. Untuk itu pimpinan perpustakaan perlu menyelenggarakan workshop digitalisasi koleksi sehingga semakin banyak staf perpustakaan yang terlibat dalam kegiatan digitalisasi maka resistensi staf perpustakaan terhadapat kegiatan digitalisasiakan menurun. 
Lantas muncul adanya kebijakan pelestarian bahan pustaka, yang ditujukan untuk menentukan tujuan perpustakaan dalam strategi pengelolaan pelestarian yang meliputi pemeliharaan, perawatan, pengawetan, perbaikan, dan reprografi. Kebijkan itu menyangkut semua aspek pelaksanaan pelestarian yang meliputi periode tertentu, umpamanya sepuluh tahun atau lebih. Proses penyusunan kebijakan pelestarian dimulai dari penelusaran, survei kondisi, dan survei fasilitas perpustakaan.

Perpustakaan Nasional Republik Indonesia merupakan Lembaga Pemerintah Non Departemen (LPND) yang melaksanakan tugas pemerintah dalam bidang perpustakaan. Yang bisa dikatakan perpustakaan induk Indonesia ini, memiliki devisi Pusat Preservasi yang dimana merupakan bagian dari Perpustakaan Nasional Republik Indonesia (Perpusnas RI ) . Yang bekerja menangani pelestarian hasil budaya bangsa, baik koleksi perpustakaan nasional atau naskah kuno nusantara. Untuk menjalankan tanggungjawab tersebut pusat preservasi bahan pustaka telah menetapkan visi sebagai pusat informasi pelestarian bahan pustaka dan naskah kuno nusantara. Dipusat Preservasi Perpusnas RI ini, dibagi menjadi Bidang Konservasi yang menangani masalah perawatan dan pemeliharaan dan teknis penjilidan, lalu Bidang Reprografi yang menangani masalah pembuatan mikro film dan reproduksi foto. Serta dilengkapi dengan Bidang Penanganan Transformasi.

Seperti yang disampaikan Ibu Sri Sumekar sebagai Kepala Pusat Preservasi Bahan Pustaka yang dikutip pada wawancara lapangan pada tahun 2016,

kegiatan pelestarian pusat preservasi bahan pustaka di Perpusnas RI meliputi proses leaf castingnd koleksi surat kabar langka, proses laminasi pada koleksi buku langka, proses enkapulasi pada koleksi peta langka, proses manding manual pada koleksi naskah kuno, proses penjilidan naskah kuno, proses pembuatan portapel koleksi koran kuno langka, proses penjilidan koran dan tabloid, proses pemasangan cover pada koleksi buku. (Wawancara, 25 Mei 2016) 
Untuk pengalihmediaan Ibu Sumekar menambahkan,

Di Bidang Transformasi Digital meliputi, proses editing dalam pembuatan e-book, proses pengemasan e-book ke dalam kepingan $C D$ dan $D V D$, proses pembuatan audio box. Dalam Bidang Reproduksi Foto Dan Reprografi meliputi proses pemotretan gambarlfoto, pemrosesan negatif film, proses pencucuian gambar pada negatif film yang terakhir pemiliharaan dan penyimpanan film pada album sebelum dilayankan. Untuk Bidang Mikrofilm meliputi proses peliputan data bibliografis bahan pustaka, proses pemotretan surat kabar langka kedalam bentuk mikrofilm. (Wawancara, $25 \mathrm{Mei}$ 2016)

\section{Preservasi Tidak Hanya Berlaku}

\section{Pada Lingkup Perpustakaan}

\section{Preservasi Perpusnas RI}

sebagai struktur yang membidangi pelestarian bahan pustaka sudah dinilai sengat lengkap dalam melakukan penyelamatan bahan pustaka. Namun preservasi tidak hanya dilakukan oleh perpustakaan saja, diluar masih ada orang-orang yang peduli akan penyelamatan bahan pustaka langka.

Untuk menyelamatkan nilai informasi agar dapat dimanfaatkan dalam waktu yang relatif lebih lama lagi dan terhindar dari kerusakan terhadap koleksi digital atau elektronik, Menurut Putu Laxman Pendit (2008: 253) ada beberapa cara preservasi digital, antara lain :

a. Preservasi teknologi (technology preservation) yaitu perawatan secara seksama terhadap semua perangkat keras dan lunak yang dipakai untuk membaca dan menjalankan sebuah materi digital;

b. Preservasi dengan cara penyegaran atau pembaruan (refreshing) dengan memperhatikan usia media (memindahkan data dari media yang satu ke media yang lain);

c. Preservasi dengan cara melakukan migrasi dan format ulang (migration and reformating) ,merupakan kegiatan mngubah konfigurasi data digital tanpa mengubah kandungan isi intelektualnya;

d. Preservasi dengan cara emulasi (emulation) yaitu proses "penyegaran" di lingkungan system, artinya secara teoritis dapat dilakukan pembuatan ulang secara berkala terhadap program computer tertentu agar dapat terus membaca data digital yang terekam dalam berbagai format dari berbagai versi;

e. Arkeologi yaitu menyelamatkan isi dokumen yang tersimpan dalam

Program Studi Perpustakaan dan Sains Informasi Universitas Wijaya Kusuma Surabaya 
media penyimpanan ataupun perangkat keras dan perangkat lunak yang sudah rusak, sehingga isi dokumen tersebut tetap dapat digunakan;

f. Preservasi dengan cara mengubah data digital menjadi analog, terutama untuk materi digital yang sulit diselamatkan dengan semua cara di atas.

Seperti yang dilakukan oleh Mas Bembi Ananto sebagai orang yang bekerja di Lokananta Surakarta sebagai Staf Remastering Lokananta. Mas Bembi disini bekerja me-remastering musik pada piringan hitam ataupun arsip-arsip media konvensional terdahulu menjadi digital sekarang. Mas Bembi mengungkapkan,

Dulu master-master dikirim dari RRI Pusat ke Lokananta, otomatis Lokananta menyimpan master-master itu. Dulu sempat berpikiran mastermaster itu dikemanakan?, jadi mastermaster yang sangat beragam seperti arsip-arsip sejarah yaa jadi kita memang-memang dulu kita katanya senior dislematakan aja kebentuk digital. (Wawancara, 22 September 2015)

Sehingga yang dimaksudkan Mas Bembi diatas agar tidak terjadi punahnya musik dan arsip dari Indonesia masa terdahulu, sehingga arsipnya bisa di selamatkan. Disamping itu juga mempermudah pengenalan dengan anak-anak jaman sekarang.
Remastering merupakan cara Lokananta mengalih mediakan master-master dari RRI (dijamannya) yang beragam seperti arsip-arsip sejarah, dan lainnya karena terlalu banyak sehingga dipermudah dengan alih media digital.

Untuk bidang perfllman, juga adanya preservasi. Seperti yang dilakukan oleh mas Edwin. Alasan mas Edwin sebagai preservasi film yakni Produksi Film Negara (PFN). Berkantor di Jalan Otto Iskandar Dinata, Jakarta Timur, PFN yang telah ada sejak zaman Belanda atau berdiri tahun 1935 yang tidak sempat dirawat hampir 12 tahun disimpan dengan kondisi kurang baik, tidak ada listrik tidak dijaga kelembabannya.

Dalam film dokumenternya yang berjudul "Reviving The Dead", Mas Edwin bekerja menyelamatkan rolrolan film yang masih bisa diselamatkan, disamping itu mas Edwin sendiri sebagai filmmaker berkesempatan membangun film sebagai media, karena menggunakan kembali alat-alat yang ada di PFN (Produksi Film Negara) ini dengan melakukan sedikit pembaharuan reparasi disana-sini sehingga menggunakan lagi media yang tidak 
dipakai. Mas Edwin mengharapkan yang ada di PFN bisa memberitahu macam-macam pihak yang peduli dengan film Indonesia untuk bisa merawat sejarah film-film agar terakses kembali oleh masyarakat. (ayofilm.org)

Beda lagi dengan mas Faiz Ahsoul yang akrab dengan panggilan mas Faiz, ia peduli pada pengarsipan koran dan majalah. Seperti koran sejak tahun 1988 hingga sekarang mas faiz masih mengarsipkan walapun tidak setiap hari up-date, namun tiap tahunnya ada. Tujuan di arsipkannya koran maupun majalah sejak tahun terbitan 1988 ini untuk menyediakan bahan riset, sehingga yang diutamakan adalah koran dan majalah kuno ataupun yang memiliki nilai sejarah, ungkap mas Faiz sebagai Koordinator Pengelola Program IBOEKOE di bawah Yayasan Indonesia Buku yang berlokasi di Sewon, Bantul, Yogyakarta. Mas Faiz memaparkan kondisi perpustakaannya bahwa, Kita masih kesulitan karena untuk merawat arsip itu butuh dana yang banyak, kan ruangan ini ber ac, kalo mau pake ac listrik bayar mahal. Akhirnya kami siasati dengan cara apa membuat kliping, alih digital dan kemudian fisiknya ditutup dengan plastic untuk menghindari debu. Untuk penyemprotan fungsi gasi, ya itu kami masih mengalami kendala dana pengelolaanya. Dan ini semacam jadi sebagai instalasi aja sekaligus dengan system katalognya berdasarkan tahun yang memudahkan kita untuk mengakses fisiknya. Jadi perawatannya masih manual lah. (Wawancara, 20 Desember 2016)

Sangat disayangkan dari ribuan koran seperti Tempo, Media Indonesia, Kompas dan Suara Pembaharuan dan lain sebagainya jika di hitung berjumlah ratusan bahkan ribuan koran ini belum ada perawatan khusus. Seperti fungigasi ataupun pengaturan suhu ruangan, sehingga berdampak koran tersebut berubah warna menjadi kuning. Untuk menyisiasati hal tersebut, mas Faiz beserta teman-temannya mengalih mediakan menjadi koleksi digital dengan cara menscan dengan alat khusus sehingga tidak terlalu banyak biaya untuk perawatannya.

\section{SIMPULAN}

Tujuan utama preservasi adalah memperpanjang eksistensi benda budaya karena memiliki nilai sejarah tinggi sehingga harus dijaga kelestariannya. Ditambah lagi pendapat 
Dureau dan Clements dalam Hartono (2016:165) menyebutkan, preservasi mencangkup unsur pengelolaan keuangan, cara penyimpanan, tenaga, teknik dan metode untuk melestarikan bentuk fisik dan kandungan informasi bahan pustaka.

Pada intinya pelestarian itu dilakukan tidak hanya mengenai buku, ternyata banyak bahan pustaka yang perlu di lestarikan. Seperti yang dilakukan Pusat Preservasi Perpusnas RI, Mas Bembi, Mas Edwin, dan Mas Faiz. Mereka semua melakukannya tidak semudah membalikan tangan, hal demikian adalah pekerjaan yang membutuhkan waktu yang lama serta dedikasi yang tinggi demi lestarinya bahan pustaka tersebut sehingga tidak musnah termakan usia. Karena semua bahan pustaka, memiliki nilai sejarah. Pasti disuatu saat nanti digunakan sebagai media untuk dipelajari kembali.

\section{DAFTAR PUSTAKA.}

\section{Buku}

Darmono. 2001. Manajemen dan Tata Kerja Perpustakaan Sekolah. Jakarta: Gramedia

Hartono. 2016. Manajemen Perpustakaan Sekolah Menuju
Perpustakaan Modern dan Profesional. Yogyakarta: Ar-Ruzz Media

Kohar, Ade . 2003 . Teknik Penyusunan Kebijakan Pengembangan Koleksi Perpustakaan : Suatu Implementasi Studi Retrospektif. Jakarta

Lasa, H.S. 2007 . Manajemen Perpustakaan Sekolah. Yogyakarta : Pinus Book Publisher

Len. 2001 . Digital Imaging: a Pratical Handbook . London: Facet Publishing

Putu Laxman Pendit . 2008. Perpustakaan Digital dari A sampai $Z$. Jakarta : Cita Karyakarsa Mandiri

Rusdi, Pohan . 2007 . Metodologi Penelitian Pendidikan. Yogyakarta : Lanarka

\section{Regulasi}

Peraturan Pemerintah Nomor 88 Tahun 1999 tentang Tata Cara Pengalihan Dokumen Perusahaan

Undang-Undang No.43 Tahun 2007 tentang Perpustakaan pada Bab VII Pasal 20

\section{Jurnal}

Ardham, Figra , Adijaya Yusuf dan Hadi Rahmat Purnama . 2015 .Penerapan Prinsip-prinsip Perlindungan Benda Budaya pada Masa Konflik Bersenjata pada Kasus Jadranko Prlic et al . Depok. Universitas Indonesia

Fabunmi, Beatrice Ayodeji; Paris, Matthew; Fabunm, Martins, Digitization of Library Resources: Challenges and Implication For Policy and Planning, International Journal of African \& African American Studies Vol. V, No. 2 Jul 2006

Kuniawati, Rini . 2011 . Alih Media Sebagai Sarna Digitalisasi 
Perpustakaan di Pusat Perpustakaan dan Penyebaran Teknologi Pertanian (Pustaka) Bogor . Surakarta : Universitas Sebelas Maret Surakarta

Mustofa. Alih Media dari Kaset Analog ke Dalam Bentuk Audio Digital Sebagai Strategi Preservasi: Studi Kasus di UPT Perpustakaan ISI Surakarta. Surakarta : ISI Surakarta

\section{Internet}

Ayo Film.org ; 2015 ; Reviving The Dead-Mini Dokmenter Tentang Preservasi Film (ON LINE) ; http://ayofilm,org/reviving-the-deadmini-dokumenter-tentang-preservasifilm-hfn/ diakses tanggal 12 Desember 2018

Solopos.com Penulis: Irawan Sapto Adhi ; 2018 ; Naskah Kuno Perpustakaan Masjid Agung Solo Disimpan di Kardus (ON LINE) ; https://m.solopos.com/soloraya/read/20 $\underline{181203 / 489 / 956543 / \text { naskah-kuno- }}$ perpustakaan-masjid-agung-solodisimpan-di-kardus/amp diakses tanggal 12 Desember 2018 